Supplement of Geosci. Model Dev., 14, 1427-1443, 2021

https://doi.org/10.5194/gmd-14-1427-2021-supplement

(C) Author(s) 2021. CC BY 4.0 License.

(c) (i)

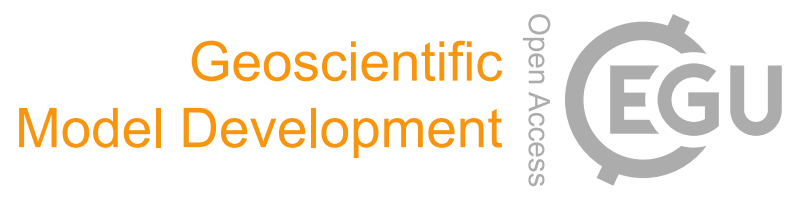

Supplement of

\title{
Effects of spatial resolution on WRF v3.8.1 simulated meteorology over the central Himalaya
}

Jaydeep Singh et al.

Correspondence to: Narendra Singh (narendra@ aries.res.in) and Andrea Pozzer (andrea.pozzer@mpic.de)

The copyright of individual parts of the supplement might differ from the article licence. 
Evaluation metrics: The following statistical metrics are used to evaluate the WRF model performance.

Mean Bias (MB)

$$
\mathrm{MB}=\frac{1}{N} \sum_{i=1}^{N}\left(P_{i}-O_{i}\right)
$$

RMSE (Root mean square error)

$$
\text { RMSE }=\sqrt{\frac{\sum_{i=1}^{N}\left(P_{i}-o_{i}\right)^{2}}{N}}
$$

\section{Correlation coefficient $(\mathbf{r})$}

$$
\mathrm{r}=\frac{1}{N-1} \sum_{i=1}^{N} \frac{\left(P_{i}-\bar{P}\right)\left(o_{i}-\overline{\boldsymbol{O}}\right)}{\sigma_{P} \sigma_{0}}
$$

Where:

$$
\begin{aligned}
& N=\text { The total number of the total pairs of observations and model simulated values } \\
& P=\text { The model values } \\
& O=\text { The observations }
\end{aligned}
$$

$\sigma_{\mathrm{P}}$ and $\sigma_{\mathrm{O}}$ are the standard deviation of the and observations.

Formula for the Linear interpolation: For any function $f$ of $x$; if the values of function at two points $x_{0}$ and $x_{1}$ is known then the value of function at any point $x$, can be calculated by the linear interpolation

$$
f(x)=f\left(x_{0}\right)+\left(x-x_{0}\right)\left[\frac{f\left(x_{1}\right)-f\left(x_{0}\right)}{x_{1}-x_{0}}\right]
$$

where $x_{0} \leq x \leq x_{1}$. 
Table S1. The summary of the statistical metrics MB, RMSE and correlation coefficient (r) for different meteorological parameters, surface pressure $(\mathrm{P}), 2 \mathrm{~m}$ temperature $(\mathrm{T} 2), 2 \mathrm{~m}$ relative humidity (RH2), 10m wind speed (WS10) and specific humidity (Q2) within all three domains d01, d02 and d03 without the altitude adjustment and after altitude correction

\begin{tabular}{|c|c|c|c|c|c|c|c|c|c|c|c|c|c|c|c|c|c|c|}
\hline \multirow[t]{3}{*}{ Parameters } & \multicolumn{6}{|c|}{ MB } & \multicolumn{6}{|c|}{ RMSE } & \multicolumn{6}{|c|}{ Correlation Coefficient (r) } \\
\hline & \multicolumn{3}{|c|}{ Without correction } & \multicolumn{3}{|c|}{ With correction } & \multicolumn{3}{|c|}{ Without correction } & \multicolumn{3}{|c|}{ With correction } & \multicolumn{3}{|c|}{ Without correction } & \multicolumn{3}{|c|}{ With correction } \\
\hline & $\mathrm{d} 01$ & $\mathrm{~d} 02$ & $\mathrm{~d} 03$ & $\mathrm{~d} 01$ & $\mathrm{~d} 02$ & d03 & $\mathrm{d} 01$ & $\mathrm{~d} 02$ & $\mathrm{~d} 03$ & $\mathrm{~d} 01$ & $\mathrm{~d} 02$ & $\mathrm{~d} 03$ & $\mathrm{~d} 01$ & $\mathrm{~d} 02$ & $\mathrm{~d} 03$ & $\mathrm{~d} 01$ & $\mathrm{~d} 02$ & d03 \\
\hline $\mathrm{P}(\mathrm{hPa})$ & 65.3 & 32.5 & 25.2 & 0.1 & 0.1 & 0.1 & 66.8 & 33.3 & 25.8 & 0.6 & 0.6 & 0.6 & 0.97 & 0.97 & 0.97 & 0.97 & 0.97 & 0.97 \\
\hline $\mathrm{T} 2\left({ }^{0} \mathrm{C}\right)$ & 2.8 & 0.9 & 0.2 & -1.1 & -1.2 & -1.2 & 3.2 & 1.6 & 1.3 & 1.9 & 2.0 & 2.0 & 0.75 & 0.67 & 0.67 & 0.35 & 0.34 & 0.36 \\
\hline RH2 (\%) & -6.4 & -0.4 & -2.4 & -8.4 & -0.9 & -3.1 & 12.1 & 8.8 & 8.9 & 12.8 & 10.0 & 10.4 & 0.43 & 0.45 & 0.52 & 0.56 & 0.39 & 0.46 \\
\hline WS10 $\left(\mathrm{ms}^{-1}\right)$ & 0.0 & 0.9 & 0.5 & 1.3 & 2.7 & 1.9 & 1.6 & 2.0 & 2.0 & 2.8 & 4.0 & 3.5 & 0.18 & 0.18 & 0.24 & 0.35 & 0.33 & 0.34 \\
\hline Q2 $\left(\mathrm{g} \mathrm{Kg}^{-1}\right)$ & 0.4 & 0.3 & -0.7 & -2.4 & -1.3 & -1.6 & 1.6 & 1.5 & 1.6 & 3.0 & 1.9 & 2.2 & 0.67 & 0.72 & 0.77 & 0.63 & 0.68 & 0.72 \\
\hline
\end{tabular}



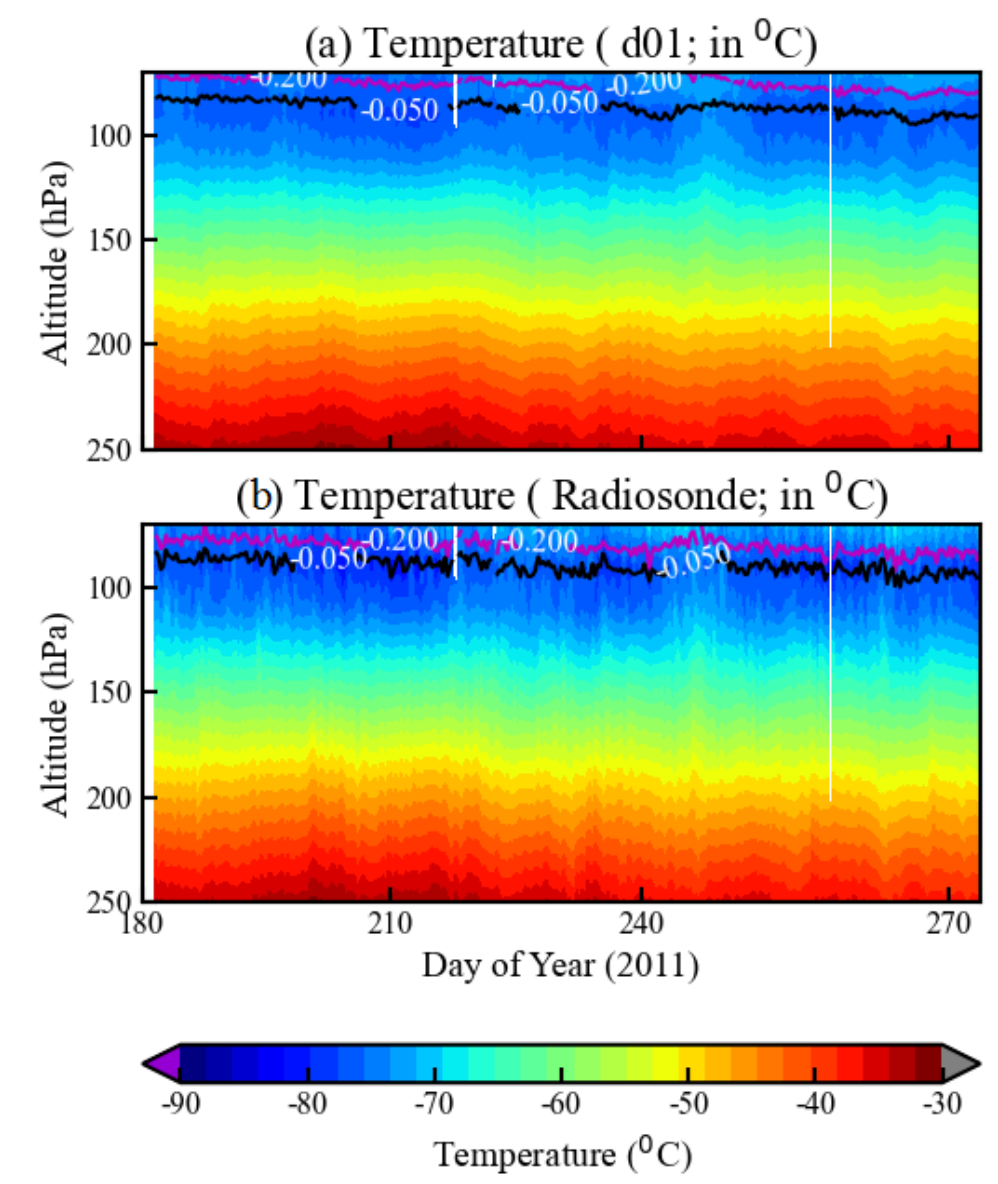

Figure S1: The zoomed version of the Figure 3a, d for which shows the contour plots of the vertical profiles of temperature. The region where dT/dt is negative is shown by two different contour lines (black: $-0.05{ }^{0} \mathrm{C} / \mathrm{hPa}$ and magenta: $-0.2{ }^{0} \mathrm{C} / \mathrm{hPa}$ ). The temperature inversion is clearly depicted in this figure. The gradient increases with altitude, which is the characteristic of this region. 

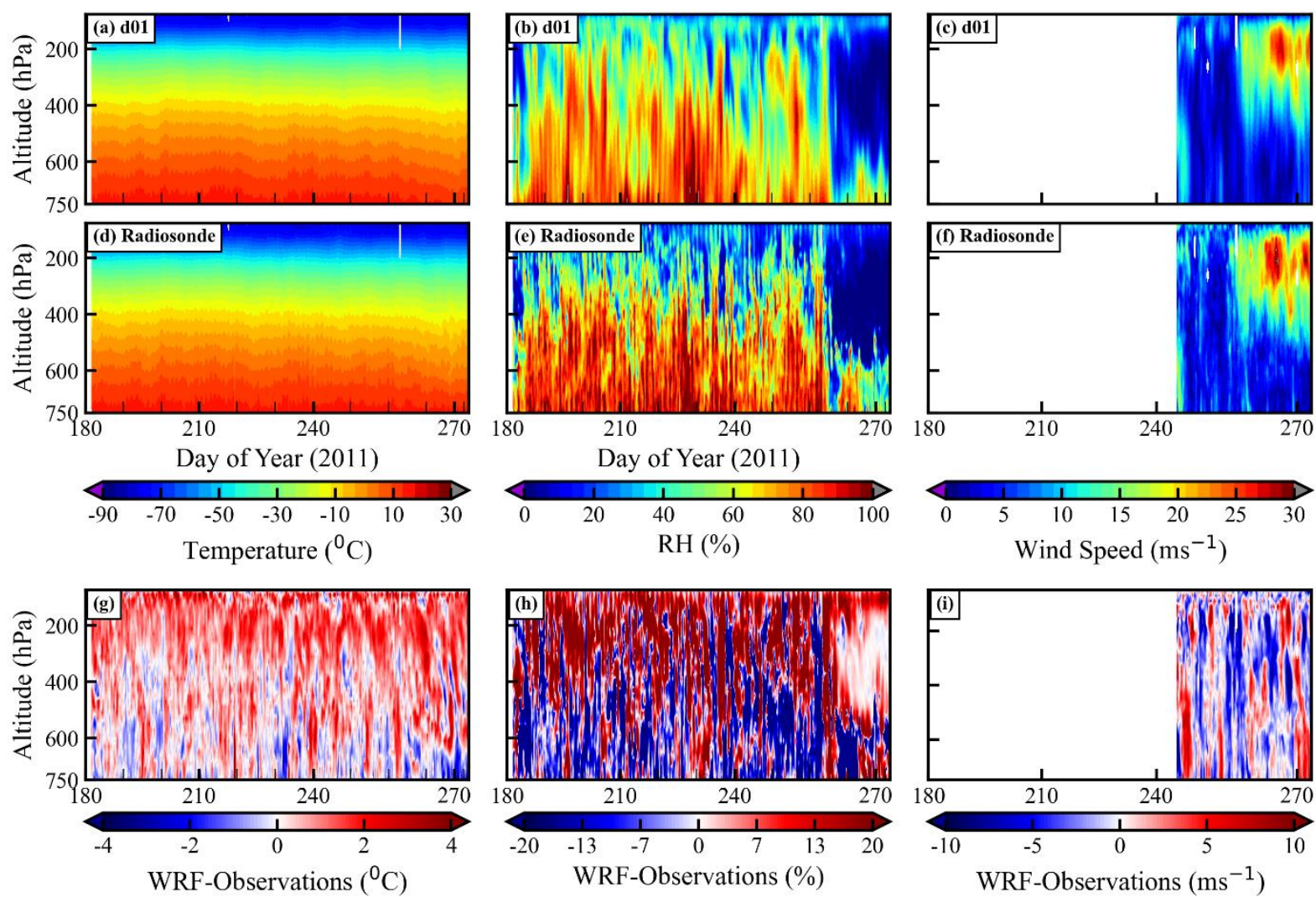

Figure S2: The comparison of $(\mathbf{a})$ temperature $\left({ }^{0} \mathrm{C}\right)$, (b) relative humidity $(\mathrm{RH} ; \%)$, and (c) wind speed $\left(\mathrm{ms}^{-1}\right)$ vertical profiles in WRF simulation $\mathrm{d} 01$ with the radiosonde observations $(\mathrm{d}$, e, and f). The x-axis of (a), (b), (d), (e), (g) and (h) show the day of the year 2011 starting from 1 July (182 $2^{\text {nd }}$ day) to 30 September $\left(273^{\text {rd }}\right.$ day). Theis figure is similar to Figure3, except the same range of $\mathrm{x}$-axis to compare the features in wind with other meteorological variables. 

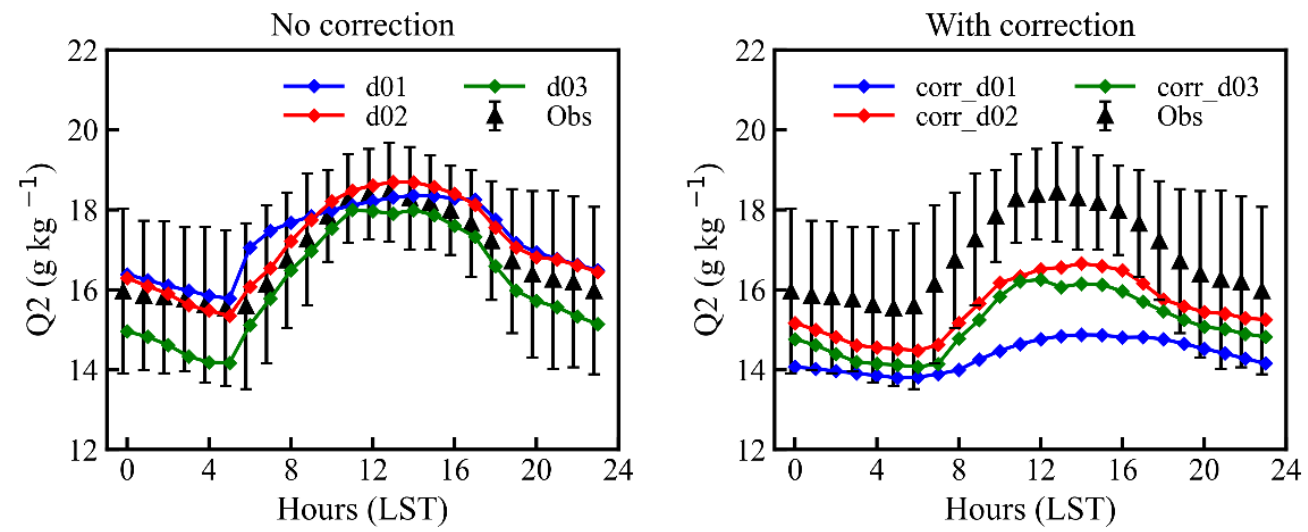

Figure S3: The diurnal variation of the $2 \mathrm{~m}$ specific humidity (Q2) in different domain. The left panel for without altitude adjustment and right panel after the correction of the altitude.
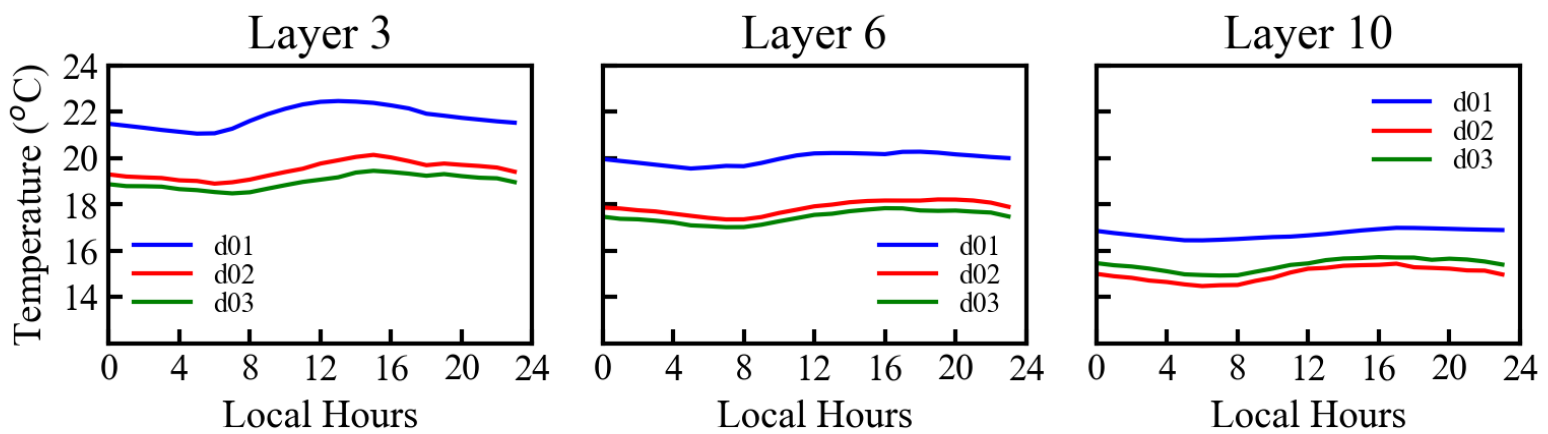

Figure S4: Comparing the temperature at the different model level (Layer 1, Layer 6 and Layer 10) at all three resolution. 
Effect of feedback (WRF-F) on correlation

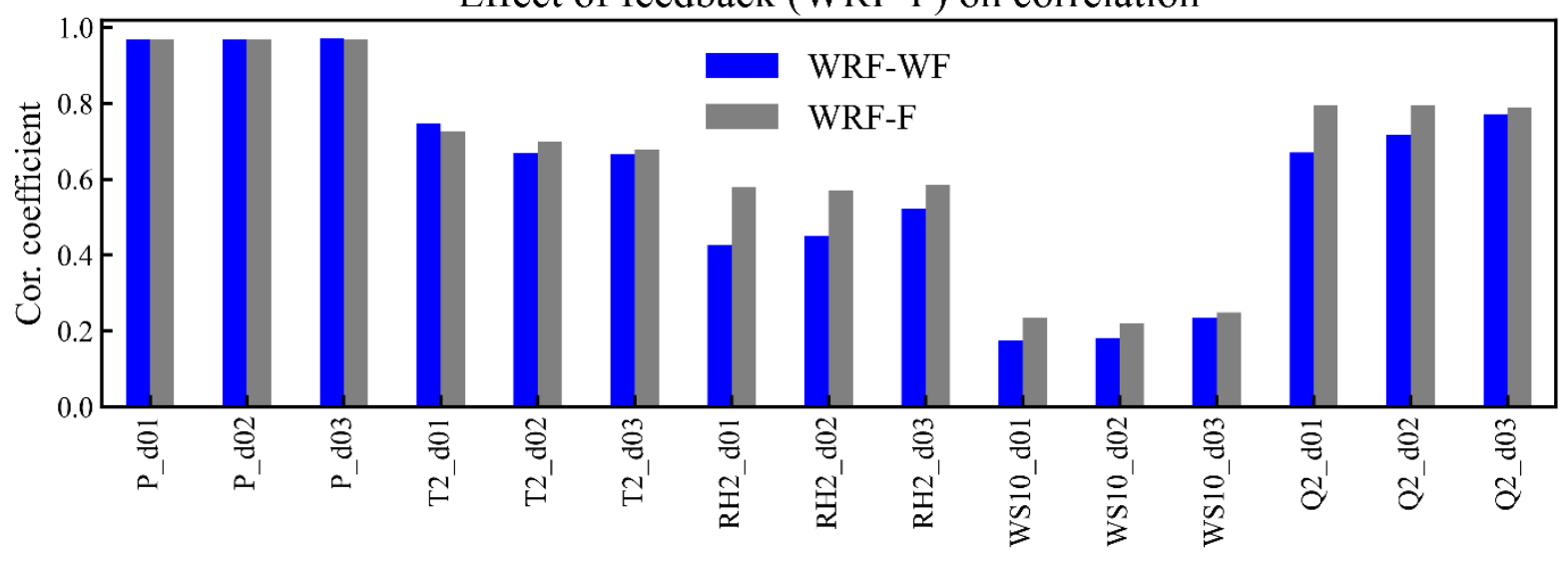

Figure S5: The comparison of the correlation coefficients without feedback (WRF-WF: blue) and with feedback (WRF-F: gray) for different meteorological parameters; Surface pressure (P), $2 \mathrm{~m}$ temperature (T2), $2 \mathrm{~m}$ relative humidity (RH2), 10m wind speed (WS10) and 2m Specific Humidity (Q2) for the different domains d01, d02 and d03

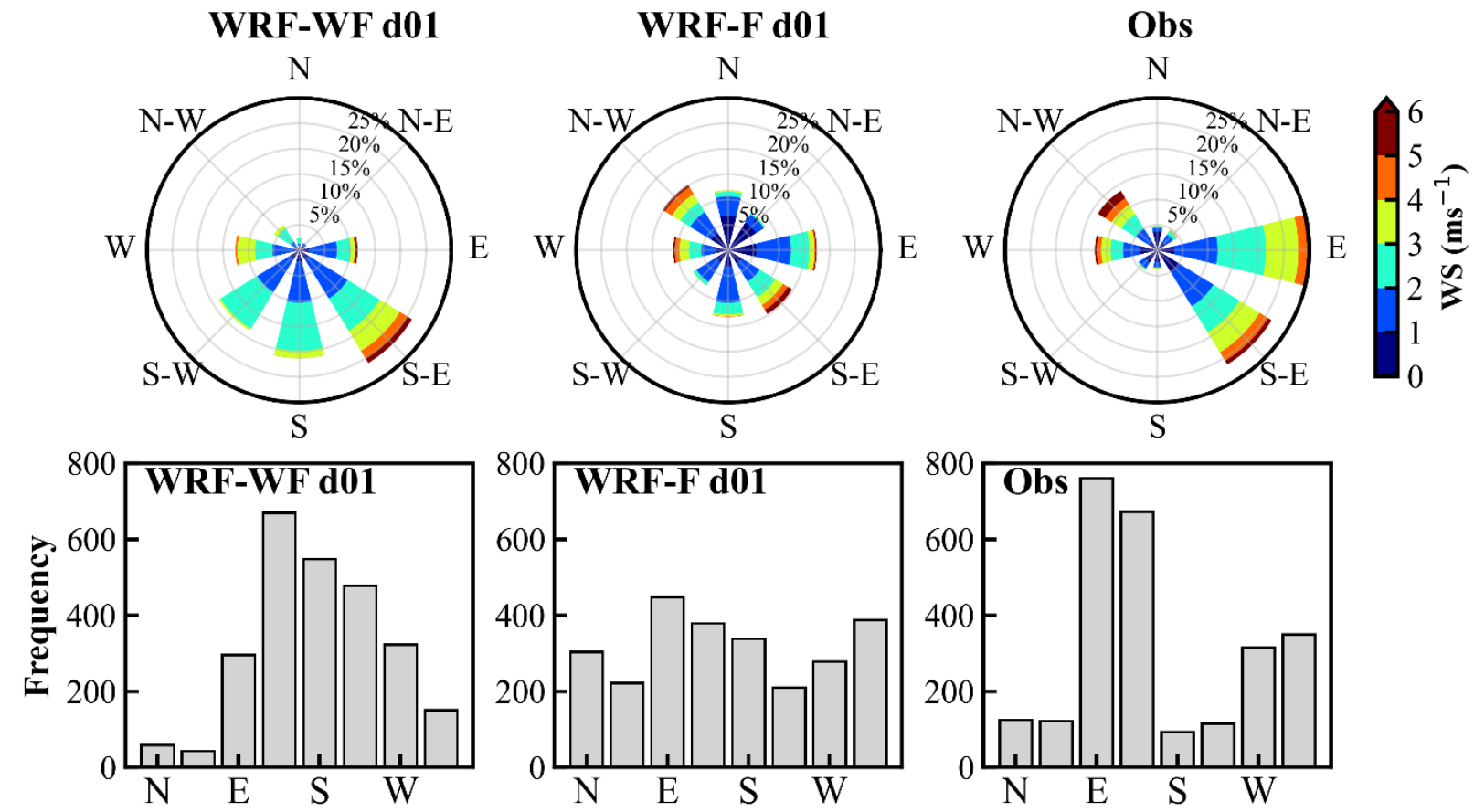

Figure S6: Comparison of the wind speed and direction is shown by the windrose diagram (first row), and frequency distribution of the wind direction (second row) for d01 without feedback 
(WRF-WF) and with feedback (WRF-F) along with the observation for the time period JuneSeptember 2011. The different colours of windrose show the wind speed and the radius of windrose show the percentage frequency of counts for particular direction.
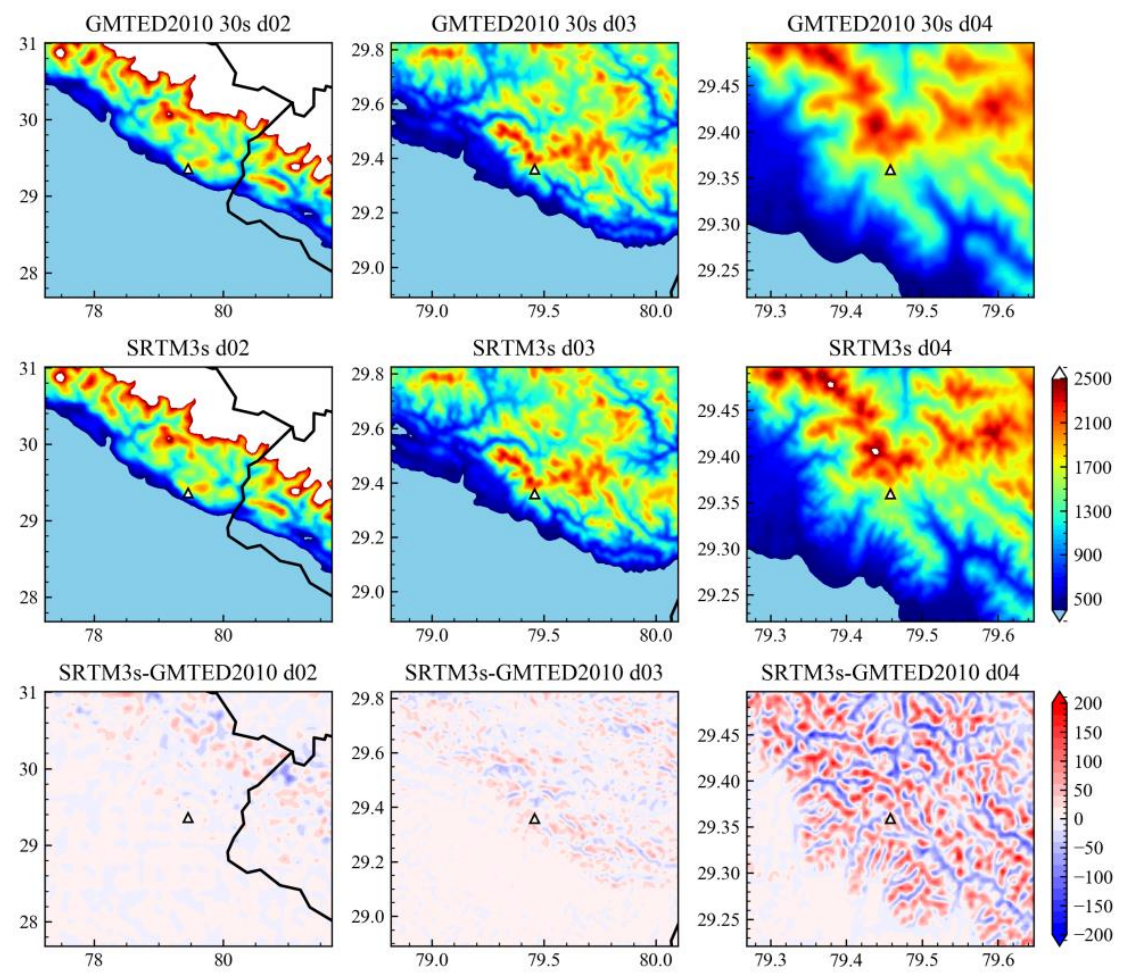

Figure S7: The topography from GMTED2010 (first row) at 30s and SRTM (second row) at 3s in three different domain $\mathrm{d} 02$, d03 and d04 while third row shows the difference between SRTM and GMTED2010. 

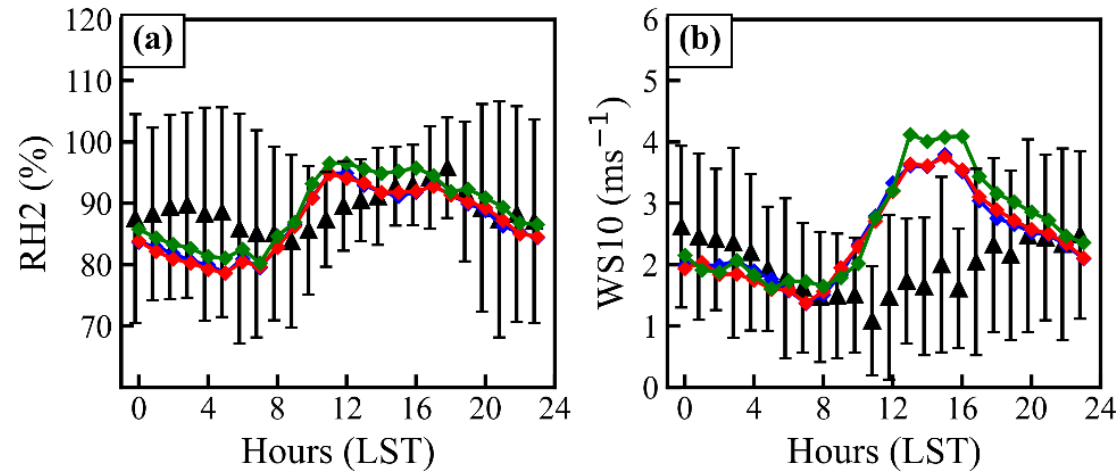

Figure S8: Diuranl variation of RH2 and WS10 in GMTED d03, SRTM d03, and SRTM d04

Table S2. The mean bias in surface pressure $(\mathrm{P}), 2 \mathrm{~m}$ relative humidity $(\mathrm{RH} 2)$ and $10 \mathrm{~m}$ wind speed (WS10) within three domains GMTED d03, SRTM d03 and SRTM d04.

\begin{tabular}{|l|c|c|c|}
\hline & GMTED d03 & SRTM d03 & SRTM d03 \\
\hline RH2 (\%) & -2.10 & -2.12 & -0.10 \\
\hline WS10 $\left(\mathrm{ms}^{-1}\right)$ & -0.48 & -0.46 & -0.60 \\
\hline Surface Pressure (hPa) & 26 & 25 & 8 \\
\hline
\end{tabular}



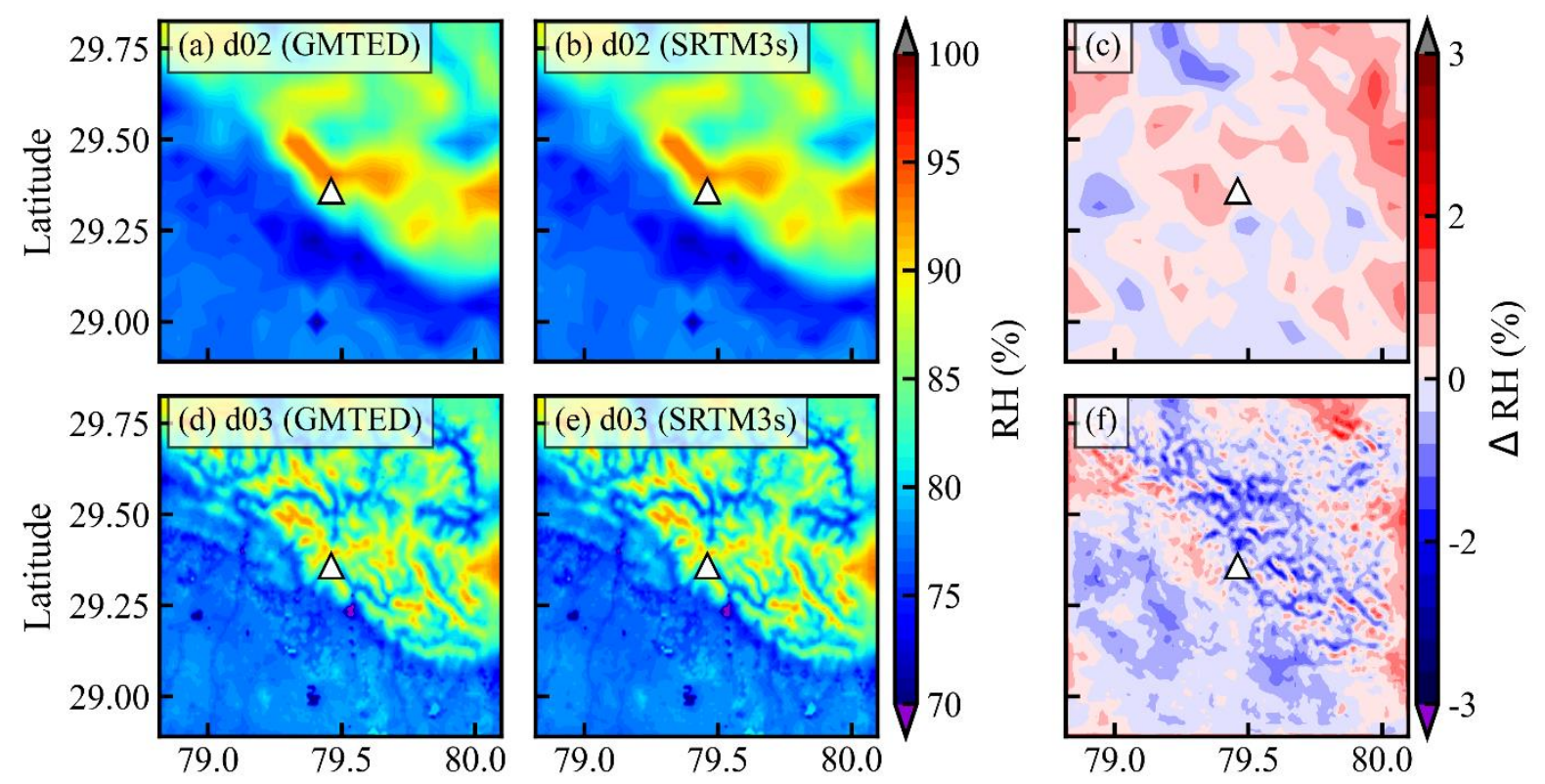

Figure S9: Mean distribution of relative humidity (RH; \%) during 1-30 September 2011 simulated by WRF model (a) d02 from GMTED, and (b) d02 using SRTM3s; (c) the difference between (a) and (b) while in d03 is shown from (d-f). The triangle shows the observation station. 